\title{
Energy Efficient Production through a Modified -Green-PPC and a Communication Framework for the Energy Supply Chain to Manage Energy Consumption and Information
}

\author{
Ulrich Brandenburg, Sebastian Kropp, Jorge Sunyer, and Daniel Batalla-Navarro \\ Institute for Industrial Management at RWTH Aachen University, \\ Pontdriesch 14/16, 52062 Aachen, Germany \\ \{Ulrich.Brandenburg, Sebastian.Kropp\} @fir.rwth-aachen. de
}

\begin{abstract}
This paper presents a definition of an energy product model through a holistic approach of energy management that recognizes both the side of the energy provider and energy consumer. Therefore, it is needed to design a model for a "Green PPC" that uses energy consumption as an additional planning and control criterion to enable a producing company to optimise and forecast its energy consumption. Furthermore, an inter-organisational information system will be described that allows an information exchange with the energy supplier to include the energy use in production planning.
\end{abstract}

Keywords: Production planning and control, energy efficiency, energy management systems, inter-organisational information systems.

\section{Introduction}

The implementation of energy management processes and tools is growing in importance for today's organisations. Especially within the manufacturing industries which are more and more reliant on the availability and efficient management of the scarce resource energy, the sensibility for this topic is heightened also on the decision making level. The decisive factors for this development are the increasing costs of energy, aspects of sustainability and an increasingly tightened regulative environment.

Increasing demand for energy coupled with a decreasing supply on the world markets results in continuously increasing prices for energy. This general development as well as the dynamics in price setting creates uncertainty for organisations with respect to accurately calculated energy costs [1]. This demand for energy efficient production is intensified by the demand of customers for sustainable products. Due to this increasing demand, organisations which are successfully able to produce efficiently can differentiate themselves from the competition. Finally organisations are forced by the developments within the regulative environment to adhere to higher standards of efficient production and introduce energy management programs. Within the regulative environment and market a shift from the individual organization 
towards its supply chain can be observed. Consequently, transparency with respect to all aspects of energy management is of the utmost importance.

On the basis of these developments it becomes clear that any activities that are carried out in isolation from relevant third parties or complementary activities with the overall goal to achieve efficiency are likely to fail or lead to suboptimal results. In alignment with [13] it must be recognized that improvements in productivity and reduction of energy consumed in the various manufacturing applications and activities may only be reached by an approach that allows for consideration of multiple activities and the involvement of relevant third parties. To allow for this flexibility and to be able to incorporate a variety of approaches, the concept of product modelling is utilized.

\section{$2 \quad$ Energy Product Model}

The aim of the energy product model is to provide the means to a holistic approach of energy management and hence induce a more efficient and effective utilization of energy. Essential within the context of energy and energy management is information about such (for example: prices, generation etc.). In the future energy as a product can be described through the information attached to it. In that sense the energy product model aims at capturing the necessary information and its streams along the energy supply chain and within the single company with the overall focus to utilize this information to improve overall energy efficiency. To provide a holistic approach that is able

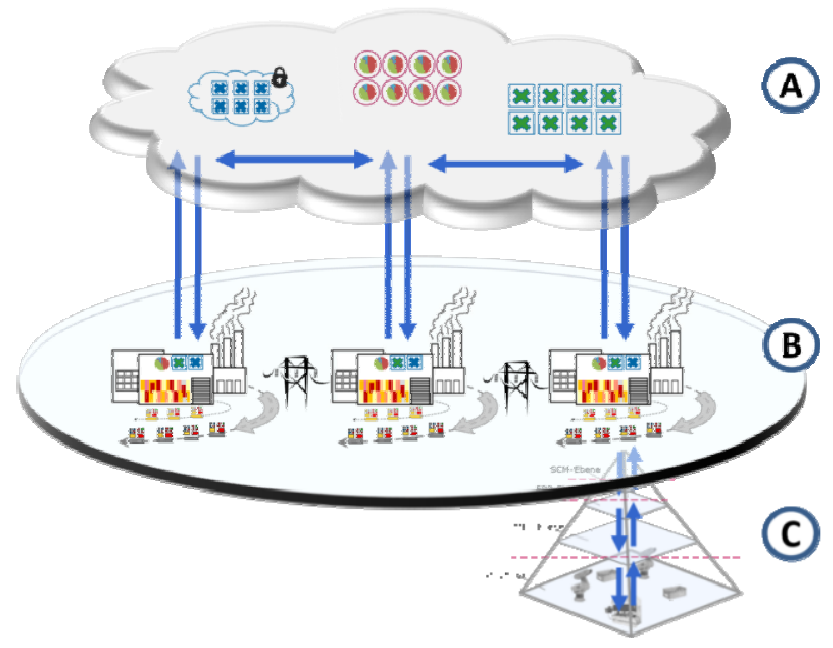

Fig. 1. Layers of the Energy Product Model 
to carter to the problems identified above the model recognizes both the side of the energy provider and energy consumer. The following paragraphs review the three levels of production, company and supply chain that encompasses the model (cf. Fig. 1).

On the production level (C) the critical variables of production planning and control are analysed. The model to be built on this level is based on the acknowledged Aachen PPC-Model [2] and extends the four reference views of the model to incorporate the aspects of energy efficient production planning and control. On the basis of the EnergyBlocks [3] concept every process will include its energy consumption information. This is necessary to be able to forecast the energy consumption of the planned processes and identify power peaking situations. In a second step the remaining power-consumption peaks caused by overlapping processes have to be timed in a way that they will not overlap anymore and thus achieve a smoother energy consumption curve resulting in overall savings of costly maximum load energy [4].

On the company level (B) the energy flows within an organization are combined with its information flows. The goal is the recording and assessment of all relevant information and energy flows from the surrounding area (Heating, Ventilation and Air condition, etc.) to the production level. In this context, energy is not perceived anymore as an overhead cost but as one that is directly linked to the single product and production phase and needs to be managed accordingly, as well as all other resources. Finally, the data that is collected within the individual organisations can be aggregated on an overarching level (A) and hence provides a connection to the energy supply chain the organization is enclosed.

\section{Intra-company Communication Framework}

Although it can be easily argued that manufacturing companies have a strong necessity to be more efficient in their usage of energy it is nonetheless at the moment quite complicated for any company to assess how their processes are performing in terms of energy efficiency. [5] underline this by establishing that until now it is not possible to classify manufacturing processes or machine tools into standards based on their energy efficiency. Considering that both operations and possible improvement measures are usually implemented at the single process level [6], the calculation of energy efficiency must be integrated in the bottom layer and then transferred to the upper levels throughout the IT-systems.

Fig. 2 gives an overview over the necessary information flows through the different layers of IT-Systems. The main reason to base the model in the Aachener PPC [2] is its vertical vision of the manufacturing companies. Consequently the proposed model represents an application and extension of the Aachener PPC model, taking energy consumption at the moment of planning the production processes into consideration. 


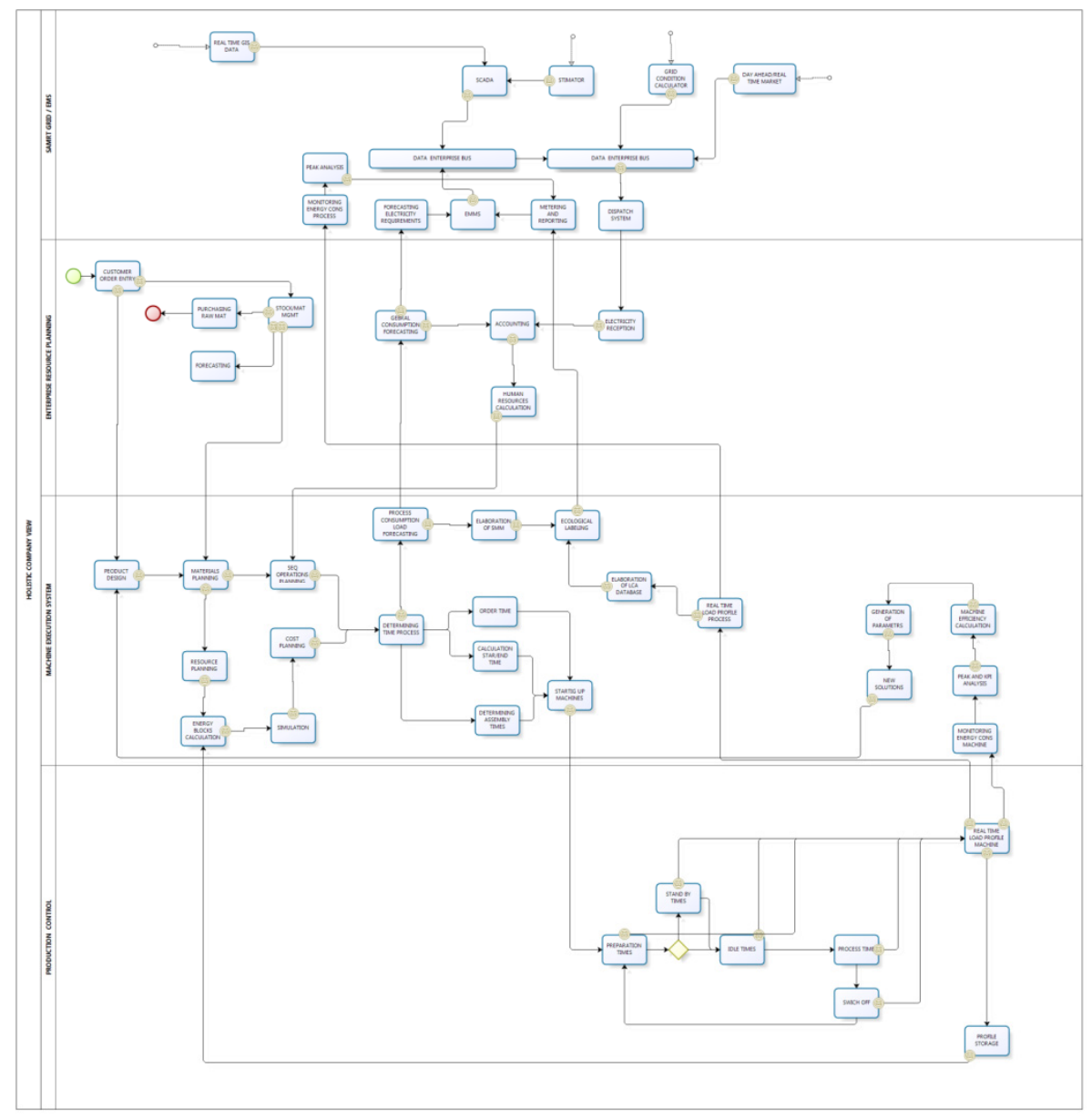

Fig. 2. Holistic Company Information View

\subsection{Connecting the Layers - Enterprise Resource Planning and Smart Grid EMS}

ERP systems need to be prepared to face and anticipate the challenge of the coming "intelligent energy delivery", which will be fully implemented based on smart grid technologies in 2020 [10].The main task concerning energy management is to define which impacts different decisions concerning energy efficiency have on the other functions of the company (e.g. Finance and Accounting) as well as production planning. In that regard a focus is put on the analysis of the costs involved with respect to energy consumption in the production plan. Additionally, a focus is placed on realtime information flows because of the rising dominance of e-business tools, which have added a higher degree of velocity within all the activities of the industry, having 
a huge impact on all the systems related with production processes, such as Customer Relations Management (CRM), Machine Execution Systems (MES) and of course the Enterprise Resource Planning (ERP) systems [11].

Overall in contrast to the Aachener PPC model [2], in the model proposed within this paper an extra layer is added corresponding to the Smart Grid systems as the communications with the energy providers are not part of the products and goods supply chain.

\section{Communication Framework for the Energy Supply Chain}

On a very basic level energy related problems can be currently categorized within either the realm of forecasting or traceability of energy consumption. The issue of forecasting encompasses the current problem that the various energy providers face with respect to accurate forecasts of energy consumption of their customers. Currently energy providers almost solely base their forecasts on data of energy consumption from the previous year. Naturally this method is rather inaccurate as energy consumption of business fluctuates for a variety of reasons and not all of these factors are stable across time. With a cloud-based service, forecasting can tremendously be improved and the single organisations that are members can feed data into it in real- time and the energy providers can then aggregate it. Basically, cloud computing describes different types of services in a layer model (infrastructure, platform, software) and distinguishes private, public, community and hybrid clouds depending on the exclusiveness of the service model [12]. Because of its abilities to facilitate data exchange between even physically and structurally different parties the cloud computing concept can play a fundamental role to solve energy related problems within the realm of both $\mathrm{B} 2 \mathrm{~B}$ and $\mathrm{B} 2 \mathrm{C}$ related issues.

\subsection{The Communication Model}

The communication within the cloud is based on interconnections between the different actors. In order to provide a good balance of energy, it is mandatory to have an accurate and reliable forecast. Communication plays a fundamental role in accomplishing this objective and must therefore be carried out with a high level of speed and reliability. Having a cloud system running the communications allows the Transmission System Operator (TSO) to better forecast energy consumption since each industry will be able to report how much energy is going to be needed in advance. Therefore, real-time usage and generation of the electricity will be monitored.

The following information model (Fig. 3) contains all the interconnections of the main actors to provide a good balance of the electricity. Renewable generators with knowledge of the weather conditions for the following days can make a first estimation of how much electricity they can provide. Based on the maximum power capability, a calculation is made by the renewable generators and forwarded to the TSO. This information will also be accessible to industries. The same procedure is carried out by non-renewable power plants that do not rely on weather conditions to make their forecast. The industries are able to access information on forecasted energy generation through the public cloud, and, given this data, they can forecast their own energy requirements. 


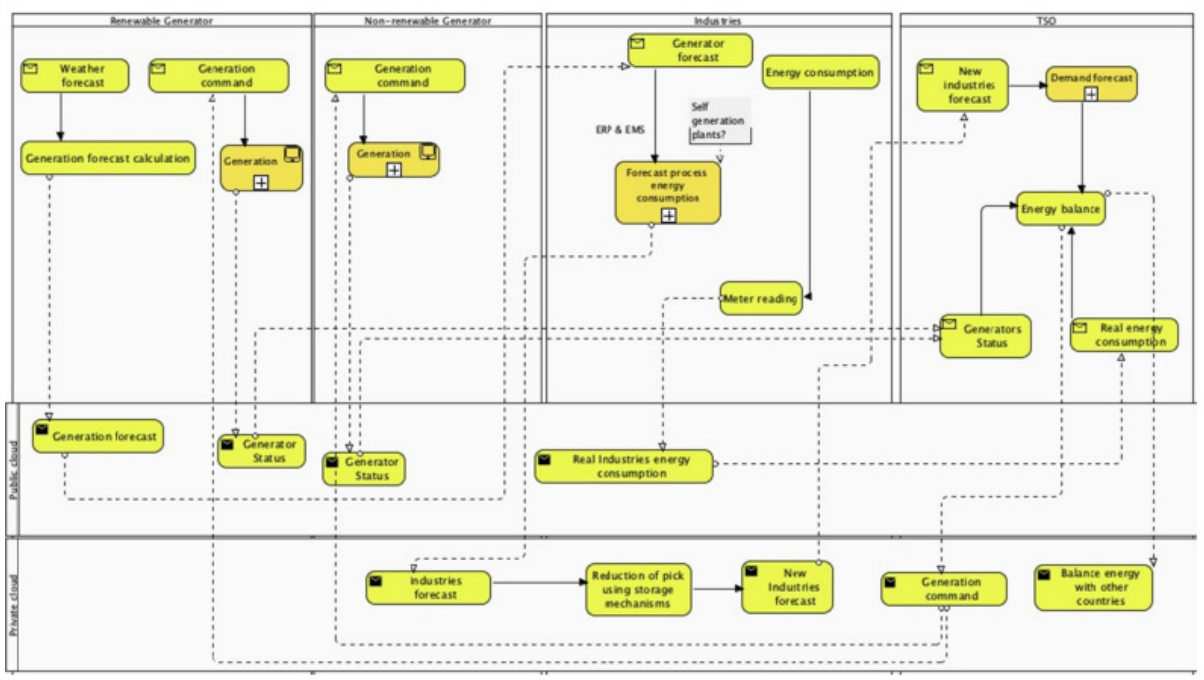

Fig. 3. Energy Supply Chain Information Model

The model offers the possibility to introduce self-generation devices to the industries. The only difference between renewable generators and the industries lies in the information; the information is kept in a private cloud and the industries can determine whether or not to use it. Before the industry forecast is sent to the TSO, the possibility to change the forecast using storage mechanisms is offered. This model also offers the possibility of making an alliance between different industries in the same physical area.

Once the TSO has all of the forecast consumption reports from the industries and the generation forecast reports, it is able to make a prediction for balancing the electricity more accurately. In order to balance the electricity load, the most important information is the quarter-hourly data regarding how much electricity is being consumed in each industry. With these three sets of reports, the TSO can better balance the electrical grid and give more accurate orders to the generators. This kind of communication system automatically results in a more efficient generation-consumption relationship.

\subsection{Balance in the Cloud}

To provide a good balance and performance of the needs and usage of the electrical grid, the TSO needs to use different EMS systems to perform the calculations. Most of this data that the different EMS systems need is pushed through the cloud. All the EMS systems being set-up in the cloud have many interconnections and different functions, but the most important interconnections and the main utilities that will be in use can be set up in a unique model map (Fig. 4). 


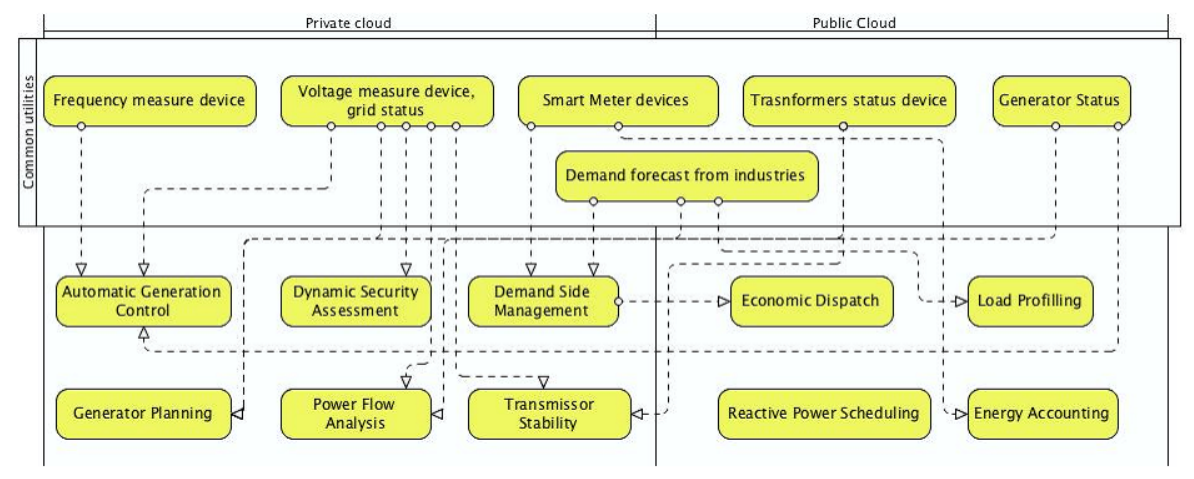

Fig. 4. EMS and Utilities

Furthermore, in the Communication Model Web-posted services are also considered. In order to provide good information of the electrical network, some data should be posted to provide clear and transparent information about the electricity or facilities. Some of these reports are mandatory by the European Union, such as Real-time demand, Forecasted demand or Real-time generation. These reports will also gather the information from the different devices used to measure or to control the demand and the status of the network.

\section{Conclusions and Outlook}

The approach to create an energy product model that gives an overall view on the intra-company and corporate information flows concerning energy efficiency is the first step towards an energy-efficient PPC. It enables an energy-efficient manufacturing by reducing costly power peaks through on optimized PPC and a more transparent consumption forecast that allows operating at a more efficient operation point. The accumulated real-time consumption-data and the consumption-forecast that are processed through the company`s system and shared with the TSO allows a network load of higher accuracy.

Further steps towards an energy-efficient production planning is the inclusion of energy-efficiency within existing target systems for production planning and control. Hence, the interdependencies between variables affecting economic efficiency and energy efficiency have to be analysed. Based on that it will be possible to define settings of parameters (e.g. order-release, lot sizes etc.) that increase the overall energyefficiency of a production system while assuring a favourable degree of economic efficiency. These settings will be highly company-dependent and have to be defined for each company individually. 


\section{References}

1. Jucker, B., Leupp, P., Sjökvist, T.: Electrical energy - The challenge of the next decades. Abb Review, 8-13 (2008)

2. Schuh, G., (Hrsg.): Produktionsplanung und -steuerung. Grundlagen, Gestaltung und Konzepte. Aufl., vol. 3. Springer, Heidelberg (2006)

3. Weinert, N.; Chiotellis, S.; Seliger, G.: Methodology for planning and operating energyefficient production systems. CIRP Annals - Manufacturing Technology 60(1), S.41-S.44 (2011)

4. Westkämper, E., Erlach, K.: Energiewertstrom. Der Weg zur energieeffizienten Fabrik. Fraunhofer-Verlag, Stuttgart (2009)

5. Schlosser, R., Klocke, F., Lung, D.: Advanced in Sustainable Manufacturing. Springer, Heidelberg (2011)

6. Li, W., Winter, M., Kara, S., Hermann, C.: Eco-efficiency of manufacturing processes: A grinding case. In: CIRP Annals - Manufacturing Technology 61(1), S. 59-S.62 (2012)

7. Putnam, B.: ISO 14031: Environmental Performance Evaluation (2002)

8. DIN EN ISO 50001: Energy management systems - Requirements with guidance for use (2011)

9. Herrmann, C., Thiede, S., Kara, S., Hesselbach, J.: Energy oriented simulation of manufacturing systems - Concept and application. CIRP Annals - Manufacturing Technology 60(1), S.45-S.48 (2011)

10. California ISO: SMART GRID - Roadmap and Architecture (2010)

11. Lee, J.: E.-manufacturing. Robotics and Computer-Integrated Manufacturing 19(6), S.501-S.507 (2003)

12. Schubert, P., Adisa, F.: Cloud Computing for standard ERP systems: Reference framework. Supply Chain Management: An International Journal (2011)

13. Rahimifard, S., Seow, Y., Childs, T.: Minimising Embodied Product Energy to support energy efficient manufacturing. CIRP Annals - Manufacturing Technology 59(1), 25-28 (2010) 